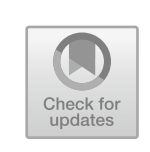

\title{
Faith and Work: Brave New World?
}

\author{
David W. Miller
}

\section{INTRODUCTION}

The venerable cultural etiquette queen of the early twentieth century, Emily Post, advised in her classic book, Etiquette in Society, in Business, in Politics, and at Home (1922) that polite company should never talk about sex, politics, or religion. These gradually became known to be the three taboos. The logic behind these taboos is that each of these topics are so emotive, so personal, and so difficult to talk about that it is simply better to avoid them. The risk of offending someone or being misunderstood is so high that it is more prudent to ignore the subjects altogether. And for almost a century the business world followed her advice. After all, in those days corporate leaders sought to conform to society, whereas contemporary leaders seek to transform society and challenge outdated and discriminatory social norms.

Businesses have typically eschewed involvement in personal or controversial subjects, wanting to protect their brand to avoid offending employees or clients and other stakeholders. So it is logical that, for decades, the corporate world has religiously followed (pun intended) Emily Post's advice that sex, politics, and religion were considered taboo subjects.

D. W. Miller $(\bowtie)$

Princeton University, Princeton, NJ, USA

e-mail: dwm@princeton.edu

(C) The Author(s) 2020

T. Akram and S. Rashid (eds.), Faith, Finance, and Economy, https://doi.org/10.1007/978-3-030-38784-6_9 
However, just because certain subjects are difficult to talk about does not in itself mean one should not try. Indeed, avoiding the discussion of taboos or other awkward subjects such as racism often causes even more problems. Indeed, many leaders and their companies have realized that the greater danger lies in ignoring important topics, regardless of how delicate or awkward they may be. And that one's brand may be harmed, and stakeholders might be upset if the company does not address issues seen as central to human identity and part of creating a diverse and inclusive workplace.

Thus, over the past few decades the three taboos have gradually crumbled, giving way to various strategies to engage and discuss sex, politics, and religion in a corporate context. Today in corporate America, and many other countries around the world, the first two taboos have largely fallen by the wayside. Sex was the first taboo to come out of the closet. Starting with new birth control methods, eventually public discourse about sexuality, sexual orientation, and more recently sexual harassment (e.g., the \#metoo movement) became normative not avoided. Admired companies, whether small or large, have developed thoughtful and specific policies to address questions of sex, including sexual orientation, sexual identity, sexual misconduct, office relationships, and sex-related medical benefits. These matters remain deeply personal and views may differ, but companies realize that to not talk about them and develop specific policies hurts business by affecting, among other things, the attraction and retention of a wider talent pool.

The second taboo, politics, has also gradually fallen. Large companies and industry associations now invest significant resources lobbying regulators and politicians for policies favorable to their industry. Many companies make it a practice of supporting candidates from both political parties so as to hedge their bets for whoever wins. And CEOs are increasingly pressured by their employees to speak out on government policies they disagree with or find offensive, including issues such as immigration, the environment, healthcare, gender, and racism. So discussing politics, while still potentially emotional and divisive has become a normative part of corporate life and conversation.

So what about the third taboo, religion? That is the subject of this chapter. Have companies come to a stage where, like sex and politics, they find business value in engaging the topic? Or is it still best to avoid the topic for fear that it remains too emotive, conflictual, and divisive? 


\section{We're Not in Kansas Anymore: Today's Workplace Context Has Changed}

In the classic 1949 movie, The Wizard of Oz, the lead character Dorothy utters a memorable line. As she is magically transported from her idyllic irenic life in the Midwest to the imaginary land of $\mathrm{Oz}$, with anxiety in her voice she says to her pet dog, "Toto, I have a feeling we're not in Kansas anymore."

One could say the same about virtually every aspect of corporate life today versus even just a few decades ago. We increasingly live and work in a digital, technology-driven economy. Phrases like the gig economy, Industry 4.0, and the like abound. The old boundaries between work and personal life are blurred. At work most white-collar workers take time to tend to personal chores. And when at home they catch up on emails, participate in conference calls, and do other forms of work via various forms of connectivity to their office, clients, and vendors. In addition, whether by choice or necessity, both white- and blue-collar workers frequently change companies and career paths. A job for life with one employer is an anachronism. And while discrimination still exists, women and minority groups are increasingly breaking down workplace barriers and gaining access to the most senior levels of virtually all sectors.

Moreover, employees of all ages, and particularly the Millennial and $\mathrm{Z}$ generations, are no longer content to live a bifurcated life. They want to bring their whole self to work and not leave an essential part of their identity or important aspects of themselves in the parking lot. They do not want to feel ashamed or hide who they are or what they believe. This applies to visible parts of their humanity such as race, ethnicity, gender, and even hairstyle or body art. And this holistic instinct also applies to often hidden or less visible parts of their identity such as gender orientation and faith.

A further change between our times and Dorothy's is language itself. Words have always mattered, but maybe even more so today. The word "religion" has itself become a very loaded term, not just descriptive. Many in the West view religion as a pejorative term, viewing it as judgmental, exclusive, and divisive. They often prefer the term "spirituality" finding it more open, inclusive, and not doctrinal. Yet some people who view themselves as "spiritual but not religious," ironically, have such a similar doctrinal certitude about their worldview that they too, exhibit the same 
judgmentalism toward religious people that they eschew in religious people. To navigate these linguistic tensions, I find it helpful to use the term "faith" as a more neutral term, one which includes both religion and spirituality. After all, one hundred percent of the population have faith. Their faith may not be theistic in nature, but they have faith in something, be it science, reason, or experience. Faith may be theistic or non-theistic. Put another way, we all have a worldview or Weltanschaunng through which we filter our experiences, actions, and beliefs, and how we find meaning and purpose.

For the purposes of this chapter, however, I largely use the term religion in deference to Emily Post's provocative trope we are investigating; whether speaking about religion at work is still taboo. I invite the reader to mentally substitute the word spirituality, worldview, or faith, if that helps follow the logic of this article.

Another driver toward removing the taboo of religion at work is the dramatic changes over the past few decades in the religious profile and practices of the United States workforce. Long gone is any sense of religious homogeneity that conceived of the country as comprised of predominately mainline Protestant Christians or Judeo/Christian in nature and culture. Due to a variety of factors, most notably immigration, the number of Catholic Christians is now $21 \%$ of the population and growing. Evangelical Protestants account for $25 \%$ of the population and black Protestants account for $7 \%$. The number of once culturally dominant mainline Protestants is shrinking and now claim barely $15 \%$ of the population. ${ }^{1}$

Of equal interest is how immigration patterns are causing a rise in nonChristian traditions, including Muslims, Sikhs, Hindus, Buddhists, and others. And finally, research reveals a significant increase in those who self-describe as spiritual-but-not-religious, agnostics, atheists, and the socalled "NONES" (pun intended) who pollsters describe as fitting none of the traditional religious categories. And these significant statistical changes to the religious landscape have almost forced the conversation upon the business world, making it a topic they can no longer avoid or consider taboo. After all, who is going to tell Indra Nooyi (a Hindu), the recently retired CEO of PepsiCo that her religious identity, or that of the vast

\footnotetext{
${ }^{1}$ Pew Research Center, “The Changing Global Religious Landscape” (2017).
} 
number of Hindus and Muslims who work in Silicon Valley that their religious identity is taboo?

Dorothy was right when she said, "Toto, I have a feeling we're not in Kansas anymore."

\section{RESEARCH INTO THE INTERSECTION OF FAITH AND WORK}

Many universities (both private and public) and non-profits are increasingly studying the subject of faith, work, and economics in the context of today's society. My own role, directing Princeton University's Faith \& Work Initiative (FWI) is but one example of many scholarly enterprises studying this phenomenon. FWI's mission is to "conduct research into faith and work, developing theoretical frameworks and practical resources for leaders in the marketplace." This involves interfaith and interdisciplinary thinking. Some of FWI's areas of research include: studying the faith at work movement; researching the nature of work, technology, and labor in the new economy; connecting ancient religious ideas and resources to modern-day marketplace concerns; developing a psychometric scale that reveals how people of all traditions manifest or live out their faith at work; and considering the role of religious traditions as a resource for business ethics.

As noted above, one theme that continually emerges in our research and that of other scholars, is that employees no longer wish or are willing to compartmentalize their life by hiding or shutting down essential parts of their being. For many people their faith, their religious tradition, or their spirituality is an important, if not central, part of their identity and humanity. But what does it mean to "bring your faith to work"? What does faith look like in the workplace? How do people integrate their spirituality and work? Isn't that going to be messy, disruptive, and cause conflict at work?

\section{The Case for "Conflicting Forces"}

It is not without good reason that many in the business world, and other parts of society have historically considered religion as a taboo subject. Let's consider some of those claims and their validity: 
- Religion is divisive-Yes, religion is a topic that can divide its various adherents. There are too many examples of religiously motivated violence, which one fears might spill over into the workplace. In some work contexts people from minority religious traditions are reluctant to voice or practice their faith for fear of discrimination.

Though religion can be divisive, it need not necessarily be divisive. Moreover, it can also, when handled thoughtfully and respectfully, be a uniting force. People of different traditions can often find common ground and mutual respect that they each believe in a divine figure even though their understandings of that may differ. Indeed, other aspects of humanity, such as race and ethnicity can also be divisive. Some might even argue that baseball and football allegiances cultivate even more hatred and violence between adherents of one team or club and another!

But scholars and practitioners rightly argue that those attributes are not prima facia divisive. Indeed, thoughtful companies have figured out how to manage through the potential conflictual issues of race and ethnicity and are now learning to do the same with faith at work.

- Religious accommodation is disruptive to the work environmentmany religious traditions require their adherents to do or not do certain actions. Some are required to pray at precise times during the day. Some are required to wear certain attire (or, conversely, not to wear certain attire). While others are forbidden to touch certain products (e.g. alcohol, pork) or be involved in certain job functions or industry sectors. And yet others might have a desire or religious duty to be absent from work to observe certain holy days or leave work before sundown on their Sabbath. Individually and collectively these and other accommodation issues can conflict with or disrupt workflows, serving customers, and other business needs.

Generally speaking, the legal test is that employers are obligated to accommodate reasonable requests of sincerely held religious beliefs or practices so long as they do not unduly disrupt the business. This rule of thumb is based on Title VII of the Civil Rights Act of 1964, which

prohibits employment discrimination based on religion. This includes refusing to accommodate an employee's sincerely held religious beliefs or practices unless the accommodation would impose an 
undue hardship (more than a minimal burden on operation of the business). A religious practice may be sincerely held by an individual even if newly adopted, not consistently observed, or different from the commonly followed tenets of the individual's religion. https://www.eeoc.gov/eeoc/newsroom/wysk/workplace_ religious_accommodation.cfm

In practical terms, this is a fairly low bar, meaning that companies can legally decline accommodation to requests they deem too disruptive. But the fundamental point is that employers have a legal obligation to at least try to accommodate religious accommodation requests. Many companies have sought to learn more about the accommodation requests and work with employees and groups sharing certain religious requirements to find creative ways to honor the employee request without causing disruption or conflict. Indeed, in a tight labor market, employers who are known to be "faith-friendly" (not to be confused with faith-based) i.e. companies who welcome and embrace people who want to bring their faith to work, become very desirable employers. Both common sense and bottom-line impact are leading enlightened companies to encourage supervisors to find creative solutions to accommodation requests and thereby to attract and retain the best talent.

- Religious harassment-harassment is a serious issue and a legitimate concern in the workplace. It is related to another serious issue known as a "hostile workplace." Workplace harassment can take many forms, including sexual, racial, and religious. Charges of religious harassment emerge when someone might be mocking or disrespecting someone for their religious beliefs, or conversely, being overly zealous trying to persuade someone to become a part of their belief system.

- Proselytizing - while proselytizing is usually considered offensive and inappropriate, many are surprised to learn that strictly speaking, it is not prima fascia illegal. It becomes illegal when the recipient states they do not wish to be the recipient of such overtures and communications. When proselytizing crosses this line, it can be deemed harassment or part of a hostile workplace, and cause for legitimate complaints.

- Quid pro quo-is a form of favoritism or discrimination where a supervisor, for example, might offer a promotion to an employee 
solely on the condition they agree to attend their church or some similar condition.

\section{The Case for “Convergent Resources”}

The above case for "conflicting forces" raises several legitimate and important points. Some of them, when viewed more closely also have a positive side (e.g. accommodation) whereas others are always conflictual and problematic (e.g. harassment). While not trying to minimalize the conflictual issues, we also note that many of these challenges are not unique to religion or faith in the workplace. Harassment, quid pro quo, and other discriminatory practices are not the sole domain of religion. Other topics and issues can also be conflicting forces in the workplace.

So why should religion be singled out as a taboo, whereas other personal and often emotive topics (e.g. gender, sexual orientation, race, and ethnicity) are seen as core parts of company diversity and inclusion (D\&I) programs and are not seen as taboo? Indeed, research and experience suggest that with appropriate education, training, and policies, the potential problems associated with other D\&I categories and groups are manageable if not largely avoidable. Moreover, there is increasing evidence-just as has been demonstrated with other forms of diversity - that faith and work, properly implemented, can bring many positive benefits to employees and the business as a whole.

If that is accurate, what then are some of the possible benefits associated with faith at work? What is the business case for not just tolerating but embracing faith and work as convergent resources? The reasons are many but before presenting them, let me first outline the four typical organizational attitudes toward or ways that companies approach the concept of faith at work ${ }^{2}$ :

- Faith-avoiding-companies that are faith-avoiding attempt to stifle or prevent any manifestation of faith at work, be it verbal, attire, items in their workspace, or use of company property for any gatherings or other uses. They generally view faith at work as conflictual, problematic, inappropriate for a business context, and generally

${ }^{2}$ Miller, D. W. and Ewest, T., "A New Framework for Analyzing Organizational Workplace Religion and Spirituality," Journal of Management, Religion, and Spirituality, Vol. 12, No. 4, 2015, 305-328. 
are unaware of or choose not to follow Title VII laws against religious discrimination at work. Some companies in this faith-avoiding category may simply not think holistically or even know that many employees want to bring their whole selves to work, including their faith.

- Faith-tolerant-companies that are faith-tolerant (or as I call them in the article, "faith-safe") will follow the minimal legal accommodation required by law but avoid full embrace of faith and work as a company policy. My research suggests that most companies today fall in this category. They are not hostile to faith at work as some faith-avoiding companies maybe, but they are reluctant if not afraid to put in place formal policies and practices to welcome this as a new form of D\&I. This reluctance may come from legal guidance or from (somewhat ironically) the chief human resources officer. These companies ascribe to the old adage, "if it ain't broke, why fix it?" The answer, of course, is that it will break someday, and the company may be on the wrong end of a wrongful dismissal or religious harassment lawsuit.

- Faith-based-companies that are faith-based are typically small or medium-sized family or owner-operated businesses who clearly state that their company values and how they conduct business are grounded in a certain religious tradition. Not surprisingly, that tradition is the religious identity of the family or owner. Thus, they strongly embrace faith at work. But they risk causing real or perceived discomfort to if not discrimination against employees or job applicants who do not ascribe to that particular religious tradition. Faith-based companies are not illegal, but if over 10 employees, they must follow the same Title VII guidelines as larger companies.

- Faith-friendly-finally companies that are faith-friendly are different than the other three approaches in several ways. First, they don't avoid or merely tolerate faith at work. Nor do they have a single espoused religious identity. Rather, they embrace faith identities as a whole, welcoming and respecting people of all faith traditions, including worldviews such as atheism and agnosticism. Indeed, all people have a worldview or a "life philosophy," whether structured or informal; something they use as a baseline or a filter for meaning, purpose, ethics, and how to live their life. 
Faith-friendly companies give all people an equal seat at the table, and equal dignity and respect. Faith-friendly companies recognize that conflicts can occur, so they invest in training, education, and having thoughtful policies that help reduce if not avoid conflictual issues that arise from religious motivations.

Some faith-friendly policies and practices are tangible and visible, while others are less tangible or visible. A company might start by creating written faith-friendly policies and including them on their web site and other internal policy materials. These would send a signal and overarching message to management, employees, and applicants that bringing your faith to work is not only okay but embraced. And that as a faith-friendly company they welcome people of all faith traditions, whatever they may be. Other examples of faith-friendly practices include but are not limited to: offering kosher and halal food in company cafeterias or meetings; trying to avoid scheduling major company or client events/meetings during known religious holidays; making conference rooms available for faith groups to meet for study, prayer, or fellowship; creating dedicated meditation or prayer rooms open to all; hosting education events to learn about various religions and their major holidays; and consider having sanctioned religious affinity groups/business resource groups with the same standing and access to resources as women's, LGBTQ+, and other D\&I affinity groups have.

Faith-friendly companies feel it is not only the "right thing to do" to embrace faith as part of D\&I and holistic thought. They also see the potential business and bottom-line benefits accruing from such creating a culture of faith-friendliness.

So what are these benefits that emerge from companies that view faith and work as convergent resources and adopt a posture of faithfriendliness? Here are but a few reasons, all of which are backed up by a growing body of research in the Academy of Management and other scholarly guilds, as well as field research and practical experience:

- Diversity \& Inclusion-most successful and admired companies articulate a strong commitment to D\&I, often citing it as a core value. Companies are quick to point out that not only is this the right thing to do, but it also brings bottom-line business benefits. Research suggests that over time diverse teams outperform homogenous teams, bring innovation, and help improve the attraction and retention of talent. Leading companies across a variety of business 
sectors, such as Deloitte, Accenture, Tyson Foods, and VMware, are also realizing that diversity should not be limited to traditional aspects such as race, ethnicity, gender, and gender orientation, but should also include socio-economic diversity, and idea, religious, and worldview diversity.

- Generational difference and trends-Millennials now constitute over $50 \%$ of the American workforce. ${ }^{3}$ And the new $\mathrm{Z}$ generation is already making its impact. Common to both is an embrace of this expanded view of diversity and inclusion that includes idea, religious, and worldview diversity. The idea of not bringing their whole self to work is inconceivable to them.

- Evidence for and trends toward holistic lifestyles-growing bodies of scholarly research in various guilds, including human resource, psychology, and management overwhelmingly find that treating employees holistically enhances a host of business metrics. This is embodied by the companies who typically appear on "most admired" and "best place to work" lists who have discovered the business benefits of supporting holistic practices. And faith or spirituality at work is one part, and for many people a central part, of living and working holistically.

- Well-being-No longer do companies ignore or stay removed from influencing the personal well-being of their employees. Today, companies realize that healthy employees are better employees. Many companies offer a wide range of personal health benefits, including subsidized (if not free) gym memberships, yoga classes, mental health resources (e.g. Employee Assistance Programs), and smoking cessation programs. Many also offer free programs to stimulate the mind, including professional development opportunities, in-house classes, and subsidized external education opportunities. A logical extension of this commitment to supporting employee well-being is for companies to consider the spiritual well-being of their employees, including developing faith-friendly policies and practices to support employee well-being. Some companies even offer chaplaincy services on workplace premises. Participation in all of these well-being programs is, of course, voluntary.

${ }^{3}$ Pew Research Center, "Millennials Are the Largest Generation in the U.S. Labor Force," http://www.pewresearch.org/fact-tank/2018/04/11/millennials-largestgeneration-us-labor-force/. 
- Links between ethical conduct and ethical foundations-I would never claim that one has to be religious or spiritual to be ethical. That claim is invalidated regularly when we see religious people doing unethical if not illegal activity. Equally, we regularly see nonreligious people who exhibit the highest moral and ethical rectitude. Some would conjecture that the key to being and remaining ethical is to have some sort of moral anchor to help keep one grounded and to have some kind North Star or reference point for guiding ethical decision-making and behavior. For many, this anchor and North Star are religious in nature, while for others it is non-theistic. For those who are engaged in a faith tradition, there is some research that suggests that people who retain close proximity to and engagement in their worship community exhibit deeper commitments to ethical conduct. Drawing on the Aristotelian teaching of habituation, many religious traditions believe that virtuous behavior can be learned and taught by emulating positive role models and the disciplined practice of virtuous behaviors. I have coined the phrase "ethical fitness ${ }^{\mathrm{TM}}$ " as a way to encapsulate that ethical conduct can be practiced and developed in the same way we can cultivate physical fitness through a healthy diet, exercise, and discipline. For many people, the foundation of their ethical fitness is grounded in their faith tradition.

\section{What Does Faith at Work Look like?}

Companies and business leaders might rightly ask, what does faith at work actually look like? How do people "bring" or manifest their faith at work? And some also ask, how do I measure this phenomenon?

With over 20 years of studying these and related questions I have come to several conclusions. Here I will share just three. First, people increasingly want to bring their whole self to work, including their faith. They no longer want to live a bifurcated life, being one person at work and a different one at home. Moreover, they are seeking meaning and purpose in and through their work, not just a paycheck. Two, many who want to do this are not sure how to do it, receiving little guidance from their worship communities or religious leaders. And three, most businesses lack a language and a framework to understand, value, and manage the faith at work phenomenon. 
To help resolve these and related questions, I have developed an instrument to help describe and measure faith and work integration. But before outlining it, it is worth remembering a few contextual realities. First, faith is multidimensional both in what one believes and the many different practices or ways one might manifest and live out those beliefs. This is true within specific faith traditions and between differing ones. Second, there is no one single or typical way of bringing one's faith to work. Moreover, it is not necessarily visible or obvious when someone has brought their faith to work. The stereotype some might conjure up when trying to picture what faith at work looks like is people who have religious bumper stickers or icons by their workspace, wear religious garb, or who talk incessantly about their faith. These stereotypes, like most stereotypes, are grounded in a partial truth but are ultimately unfair and inaccurate caricatures. In my research I seek to go beyond the misleading and incomplete stereotypes of integrating faith and work to discover and paint a much more complete, diverse, and inclusive picture.

Based on empirical research into hundreds of organizations and thousands of people, I have concluded that there are four typical ways that people bring their faith to or manifest their faith at work. I call these the Four Es. And each of the Four Es has two suborientations. My research also suggests that most people have a natural predisposition (whether conscious or subconscious) to accent one of the Four Es or their underlying suborientations. These manifestations are found in most major faith traditions. And prescriptively, I would argue that all of these manifestations have valid theological underpinnings.

I call this framework or typology "The Integration Profile ("TIP") Faith and Work Integration Scale" or TIP for short. ${ }^{4}$ Building from my original theoretical model in God at Work: The History and Promise of the Faith at Work Movement, ${ }^{5}$ and with the help of gifted colleagues Tim Ewest, Mitch Neubert, and Nicoleta Acatrinei (each of whom contributed expertise in psychometric scale development), we have developed this instrument called TIP. It allows people of any faith tradition to learn what their natural faith/work integration tendencies are and the relative strength of or lack of focus they have on each of the Four Es.

${ }^{4}$ Miller, D. W., Ewest, T., and Neubert, M., "Development of the Integration Profile (TIP) Faith and Work Integration Scale," Journal of Business Ethics, January 2018, 1-17.

${ }^{5}$ Miller, David W., God at Work: The History and Promise of the Faith at Work Movement (New York: Oxford University Press, 2007), 220pp. 
We are find that individuals, companies, and even congregations are interested in using TIP as a way to understand themselves and others better. Organizations are particularly interested in their aggregate profile and want to conduct further research to see if any TIP variables have salience and impact on other important business metrics such as engagement, satisfaction, ethics, meaning, purpose, client service, etc. It is too soon to tell if there are any generalizable patterns or possible correlations, what differences might exist between the for-profit and non-profit sectors, and what distinctions might exist between international data sets or faith traditions. Dr. Acatrinei and I are currently gathering international data sets and exploring these and other related questions.

Here is a brief description of TIP's Four Es and their suborientations, i.e. the eight overall ways people manifest their faith at work:

- Ethics - those in the Ethics profile tend to live out their faith at work with a focus on ethics, as informed by or grounded in the teachings of their faith or worldview. For some, this means a suborientation focus on personal ethics and behavior, and on one's own conduct (e.g. not cheating on expenses or lying to a client). This often involves the intentional cultivation of "ethical fitness." This is a term I have coined that implies dedication to developing disciplines, habits, and preparation to have readiness for ethical situations, in the same way that athletes develop physical fitness to prepare for competitive events. For others in the Ethics profile the suborientation focus is on social ethics, i.e., the larger ethical impact of their organization's products and services on their clients and wider society (e.g. do our products cause injury to people or harm the environment?).

- Experience-those in this profile want to experience meaning and purpose in their work. They want work to be more than a paycheck. Their faith helps them experience their work as a calling, having spiritual value and significance. For some, the suborientation focus is on the intrinsic nature of the work itself that feels like a calling (e.g. being a master craftsman, writing beautiful code, mowing a lawn perfectly, diagnosing a medical problem). For others, the suborientation is not the job task itself that brings them meaning per se, but they experience delight in being part, however small, of the overall process that made the end product or service (e.g. working on factory line but knowing your company makes safe, affordable, high quality food products or cars to help others live a better life). Notably, to 
experience work as a calling (whether in the job function itself or being proud of the end product) does not require the work to be highly remunerative or of a high social standing. Executives, doctors, and lawyers, as well as hourly workers, check-out clerks, and cab drivers can all experience meaning and purpose in or through their work.

- Expression-those who are drawn toward the Expression profile as the way they manifest their faith at work often feel a desire or in some cases a religious duty to express their faith at work. For some, the suborientation focus means verbal expression where talking about and sharing their faith with others is important. While for others, the suborientation focus is an accent on non-verbal means of expressing their faith. This expression could involve wearing specific attire (e.g. a cross, yarmulke, headscarf) or displaying a symbolic object in their workplace (e.g. a Bible, a statue of the Buddha, or a dreamcatcher).

- Enrichment-people who are drawn to the Enrichment profile tend to focus on the ways their faith helps them practice and cultivate inner growth and strength in times of workplace challenges, pressure, or stress. This manifests itself in regular prayer disciplines, devotional practices, and contemplative disciplines that tend to the inner soul, helping to heal and strengthen. For some, their Enrichment suborientation practices are very private and done by alone themselves, perhaps early in the morning before work, or quietly in their office or somewhere at their place of work. For others, their suborientation prefers sharing and finding comfort in community, and engaging their Enrichment practices in a group with others.

\section{CONCLUSION}

We started this chapter pondering whether Emily Post's so-called three taboos at work-not talking about sex, politics, or religion-should still be the norm in business today, with a particular interest in the taboo on religion. We quickly observed that discussing, thinking about, and developing corporate policies around sex and politics are normative today. So, we probed the third taboo, religion. Dorothy helped us realize that we are not in Kansas anymore. Today's workplace context has changed; we no longer live in the business world of 1922 like Emily Post. And as regards religion no longer being a taboo at work, we asked, is that a good thing? 
We made a case for faith and work as conflicting forces and as converging resources. As part of this, we introduced a framework for analyzing the four typical ways companies address the phenomenon of faith at work, ranging from trying to stifle it to embracing it.

I concluded that publicly traded and other larger companies who embrace faith-friendly policies and practices will find it beneficial to employees themselves and to the company's bottom line. And finally, we addressed a simple but not-so-simple question, what does faith at work look like? Here I introduced The Integration Profile Faith and Work Integration Scale, more commonly known as TIP, to help provide a language and framework to talk about faith, religion, and spirituality in nonemotive, respectful, informative ways, and constructive ways.

Time will tell whether conflictual forces of the world will insist religion is still a taboo topic in the work world. Or will companies discover and embrace that, done in a faith-friendly way, faith and work are indeed convergent resources. To be continued...

\section{BIBLIOGRAPHY}

Miller, David W. God at Work: The History and Promise of the Faith at Work Movement, 220p. New York: Oxford University Press, 2007.

Miller, D. W., T. Ewest, and M. Neubert. "Development of the Integration Profile (TIP) Faith and Work Integration Scale." Journal of Business Ethics (2018), 1-17.

Miller, D. W., and T. Ewest. "A New Framework for Analyzing Organizational Workplace Religion and Spirituality." Journal of Management, Religion, and Spirituality, 12, no. 4(2015): 305-328.

Pew Research Center. "The Changing Global Religious Landscape" (2017).

Pew Research Center. "Millennials Are the Largest Generation in the U.S. Labor Force" (2018). http://www.pewresearch.org/fact-tank/2018/04/ 11/millennials-largest-generation-us-labor-force/. 
Open Access This chapter is licensed under the terms of the Creative Commons Attribution 4.0 International License (http://creativecommons.org/licenses/ by $/ 4.0 /$ ), which permits use, sharing, adaptation, distribution and reproduction in any medium or format, as long as you give appropriate credit to the original author(s) and the source, provide a link to the Creative Commons license and indicate if changes were made.

The images or other third party material in this chapter are included in the chapter's Creative Commons license, unless indicated otherwise in a credit line to the material. If material is not included in the chapter's Creative Commons license and your intended use is not permitted by statutory regulation or exceeds the permitted use, you will need to obtain permission directly from the copyright holder.

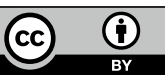

